1 Sorahan T, Gilthorpe MS. Non-differential misclassification of exposure always leads to an underestimate of risk: an incorrect conclusion. Occup Environ Med 1994;51: 839-40.

2 Loeve M. Probability theory. Princeton: D Van Nostrand, 1962.

3 Dosemeci M, Wacholder S, Lubin JH. Does non-differential misclassification always bias a true effect toward the null value? $\mathrm{Am} \mathcal{F}$ Epidemiol 1990;132:746-8.

4 Weinberg CR, Umbach DM, Greenland S. When will non-differential misclassification of an exposure preserve the direction of a trend? Am $\mathcal{F}$ Epidemiol 1994;140:565-71.

5 Wacholder S, Dosemeci M, Lubin JH. Blind assignment of exposure does not always prevent non-differential misclassification. $\mathrm{Am} \mathcal{f}$ Epidemiol 1991;134:433-7.

6 Flegal KM, Keyl PM, Nieto FJ. Differential misclassification arising from non-differential errors in exposure measurement. $A m ~ \mathfrak{F}$ Epidemiol 1991;134:1233-44.

7 Wacholder S. When measurement errors correlate with truth: surprising effects of nondifferential misclassification. Epidemiology 1995;6:157-61.

Author's reply-Our short report on the properties of non-differential misclassification of exposure, as judged by computer simulations, has prompted Wacholder et al to make several useful observations. ${ }^{1}$ These observations include a restatement of what we judged to be the "more important" feature of the simulations. We concluded (to paraphrase) that for any particular epidemiological study that investigates a causal risk factor and in which each study subject had the same probability of being misclassified (with respect to a single binary exposure variable), it would be incorrect to infer that the measure of effect obtained from the study-for example, relative risk or rate ratio-could only be increased if more reliable information were to be obtained such that all misclassification could be removed. We are pleased to learn that Wacholder et al are of the opinion "that this is an important point for readers to appreciate". We did not find those results of the computer simulations that supported this conclusion to be "disturbing"; they seemed to us to be intuitively obvious. What disturbed us was the fact that many researchers are convinced that the removal of non-differential misclassification of exposure from their studies can only increase the point estimate of relative risk (or rate ratio).

Why is our conclusion so little known? We have three possible explanations; all could be prompted by the comments of Wacholder et al. It may be because of confusion about the definition of non-differential misclassification. We chose the definition that "all exposed and nonexposed subjects have the same probability of being misclassified (these two probabilities may be different, one must be not zero)". Wacholder et al describe this as misclassification "treated as a process". They note that non-differential misclassification may also be defined in terms of "realisation" in a given data set-that is, the same fraction of diseased and non-diseased subjects were, in fact, misclassified. The first definition seems more relevant to study settings. Under the second definition, non-differential misclassification would rarely occur and a researcher would not be aware when it had occurred. (It would never occur when there was an even number of diseased subjects and an odd number of non-diseased subjects!)

A second explanation is the influence of textbook examples in which misclassifica- tion is invariably shown to operate on a proportionate rather than a random basis. We choose not to believe that errors are made every $n$th record and prefer to believe that random misclassification is more relevant to study settings.

A third possible explanation is the way in which the word bias is interpreted. Sometimes the word is used to indicate a tendency toward a given distortion, and sometimes (perhaps incorrectly) to indicate a distortion that will occur on each and every occasion-for example, in the game of bowls, the oblique course of a bowl due to its lopsided form is said to be due to bias. If the first definition were in universal use, our conclusion would be well known.

Our short report may be viewed as a call for more appropriate interpretation of study findings. ${ }^{1}$ The observations of Wacholder et al may be viewed in the same light. TOM SORAHAN Institute of Occupational Health MARK S GILTHORPE Department of Public Health and Epidemiology, University of Birmingham, Edgbaston,
Birmingham B15 2TT

1 Sorahan T, Gilthorpe MS. Non-differential misclassification of exposure always leads to an underestimate of risk: an incorrect conclusion. Occup Environ Med 1994;51: 839-40.

NOTICES

For a good working life. ICOH'96, the 25th International Congress of Occupational Health. Stockholm, Sweden. 15-20 September 1996.

The Congress will present the latest research discoveries in occupational health as well as provide a forum for exchange of ideas between practitioners and researchers.

This ICOH Congress will be noted by the introduction of new subjects of great concern to the society of today and tomorrow, such as work organisation, psychosocial factors, and gender research. A large number of minisymposia will form a bridge between the more traditional occupational health research and the new challenges of promoting a good working life.

\section{MINI SYMPOSIA}

A large part of the conference will be mini symposia arranged by the permanent Scientific Committees, such as "chemicals and allergies", "occupational health nursing in the future", "occupational health in small industries". More than thirty mini symposia will give the participants a unique opportunity to keep up with the rapid developments in occupational health.

MORE THAN 1000 PRESENTATIONS

The Congress also invites participants to present their own papers on many areas of relevance to the working environment. There will be more than 1000 oral presentations and posters.
PROMINENT KEYNOTE SPEAKERS

Eight internationally known scientists are invited as keynote speakers:

- Gender and work. Joan Acker, University of Oregon, USA

- Occupational health-a global perspective. Jerry Jeyaratnam, National University Hospital, Singapore

- Participatory approaches in occupational health. René Loewenson, Zimbabwe

- What can health professionals do to prevent muskuloskeletal disorders? Philippe Mairiaux, Université Catholique de Louvain, Brussels, Belgium

- Working conditions and cardiovascular diseases. Johannes Siegrist, Institut für Medizinisches Soziologie, Düsseldorf, Germany

- Dose concepts in occupational exposure assessments. Thomas J Smith, Harvard School of Public Health, Boston, USA

- Promoting safe behaviour. Carin Sundström-Frisk, National Institute of Occupational Health, Stockholm, Sweden

- Electromagnetic fields and cancer. Gilles Thériault, McGill University, Montreal, Canada.

The conference is sponsored by multinational and Swedish companies. Major sponsors are AMF Trygghetsförsäkring, SmithKline Beecham, Pasteur Mérieux MSD and the Swedish Power Association, Svenska Kraftverksföreningen. Other sponsors are Samhall and SI, the Swedish State Railways. The official airline is SAS. There will be an exhibition in conjunction with the conference. Companies and organisations interested in taking part should contact the ICOH'96 secretariat.

Authorised press is welcome to cover the Congress.

For further information contact: Arne Wennberg, secretary general ICOH'96, Lars Grönkvist, press officer ICOH'96, Elisabeth Lagerlöf, information ICOH'96, Maud Werner, secretariat ICOH'96,

National Institute of Occupational Health

S-171 84 SOLNA, Sweden. Tel (+46) 8 73091 00; Fax (+46) 8820556

Broadening the Limits of Occupational Hygiene. 14th Annual Conference of the Australian Institute of Occupational Hygienists. 11-13 December 1995. Adelaide, South Australia.

A three day conference (11-13 December) and two days of continuing education sessions (9-10 December). This conference will run back to back with the 31 st Annual Conference of the Ergonomics Society of Australia at the same venue.

An exceptional line up of international and local speakers include

- Professor Morton Lippmann, New York University. Inhalation Toxicology and Regulatory Policy

- Associate Professor Harriet Burge, Harvard University. Bioaerosols

- Professor Jens Rasmussan, Copenhagen University. Human Computer Interaction and Human Error

- Dr Jim Stewart, ex vice president Dupont Canada. Safety Performance and Organisational Change 